\title{
Treatment of persistent pulmonary hypertension of the newborn: update
}

\author{
Yousef K Abu-Osba
}

Persistent pulmonary hypertension of the newborn is primarily characterised by persistence of, or return to, the suprasystemic pulmonary vascular resistance and pressure normally found in the fetus. The increased pulmonary pressure causes right to left shunting through the ductus arteriosus or the foramen ovale, or both. The resulting hypoxaemia and acidosis may produce further pulmonary vasoconstriction and lead to a vicious cycle of shunting, hypoxia, and acidosis.

\begin{abstract}
Aetiology
About half the pulmonary arteries in a newborn infant contain muscle. Abnormal formation of muscle in the small pulmonary arteries can occur before or after birth and is characteristic of all forms of pulmonary hypertension in childhood. Smooth muscle precursors (the pericytes and the intermediate cells) can develop into mature smooth muscle cells within days if 'switched on' by an effector-for example, hypoxia, increased pulmonary pressure or blood flow, mediators, or endothelial cell damage. ${ }^{2}$ These changes in turn reduce the total pulmonary cross sectional area either directly or by enhancing thrombosis. ${ }^{3}$ Persistent pulmonary hypertension of the newborn was initially described in asphyxiated infants who were cyanosed with relatively normal lungs, and right to left shunting in infants without congenital cyanotic heart disease. Infants with persistent pulmonary hypertension of the newborn are usually full term or post term infants, and often have had perinatal asphyxia (13\%), meconium aspiration $(66 \%)$, or diaphragmatic hernia, pneumonia, or sepsis $(21 \%) .^{4-7}$
\end{abstract}

\section{Incidence}

Accurate estimates of the incidence of persistent pulmonary hypertension of the newborn are not available, but estimates of about $1 / 1500$ live births with a range from $1 / 1454$ to $60 / 2602$ have been reported, which accounts for about $1 \%$ of admissions to neonatal intensive care units. ${ }^{78}$

Perinatology/Neonatology Section, Paediatric Department, MBC 58, PO Box 3354, King Faisal Specialist Hospital Specialist Hospital and Resea Saudi Arabia

Correspondence to: Dr Abu-Osba. and among those with $\mathrm{A}-\mathrm{aDO} \mathrm{a}_{2}$ of $79 \cdot 8 \mathrm{kPa}$ or more for 12 hours the mortality was $94 \%{ }^{5}$

\section{Clinical presentation}

Persistent pulmonary hypertension of the newborn may present with severe hypoxia, severe acidosis, tachypnoea, tricuspid or mitral regurgitation, patent ductus arteriosus, hypovascularity on the chest radiograph, relatively clear lung fields and no anatomical cardiac lesions. The patient may develop right ventricular heave, electrocardiographic changes of myocardial ischaemia, and right ventricular overload. The disease may present immediately after birth-for example, in asphyxiated infants or those with diaphragmatic hernia with severe lung hypoplasia. It may present after 4-12 hours (subacute)-for example, in infants with meconium aspiration syndrome, or it may present after 12-24 hours (late)-for example, infants with sepsis and those with progressive airways obstruction. ${ }^{479}$

\section{Treatment}

The aetiological diversity of the disease means that no single treatment will be uniformly effective. No controlled comparisons of treatments have been carried out. Once it has been diagnosed, therapeutic efforts should be simultaneously directed towards the specific treatment of the particular cause suspected and towards the reduction of pulmonary vascular resistance. All infants should be given a broad spectrum antibiotic. Adequate blood pressure should be maintained with vasoconstricting drugs and fluid infusions. Alkalis should be given to achieve a normal arterial $\mathrm{pH}$ if there is metabolic acidosis. Mechanical hyperventilation has been used to decrease pulmonary pressure and achieve normal oxygenation. ${ }^{4}$ A very low carbon dioxide tension has a potentially deleterious effect on cerebral and renal blood flow. Complications include chronic lung disease (31\%) and pneumothorax (45\%). ${ }^{9}$ Muscle relaxants and sedatives are used to prevent agitation and fluctuations in oxygen tension. Extracorporeal membrane oxygenation has been used to treat persistent pulmonary hypertension of the newborn with varying degrees of success, and survival has been reported as ranging from 58 to $100 \%{ }^{5} 10$ Several serious complications have been reported, however, and this type of treat- 
ment is not available at most neonatal centres. A conservative approach has sometimes been used, ${ }^{11}$ but I know of no controlled trials that test the efficacy of this treatment.

Pulmonary circulation vasodilators

There are no drugs that specifically. dilate the pulmonary vasculature and reduce pulmonary hypertension. Consequently our experience has been limited to trials of vasodilators that have been developed to control systemic hypertension with variable success.

ARACHIDONIC ACID AND ITS METABOLITES

Archidonic acid metabolites play an important part in the normal regulation of pulmonary vascular tone and in the pulmonary vascular responses to various pathological stimuli. ${ }^{12}$ There are two pathways of arachidonic acid metabolism, which synthesise most of the biologically important eicosanoids: the cyclo-oxygenase pathway that generates prostaglandins $\left(\mathbf{E}_{2}, \mathbf{D}_{2}\right.$, and $\left.\mathbf{I}_{2}\right)$ and thromboxanes, and the lipoxygenase pathway that catalyses the formation of leukotrienes and hydroxy acids. ${ }^{13}$ Inhibitors of these enzymes modify the calcium dependent responses in isolated smooth muscle and white cells. There is evidence that high concentrations of lipoxygenase inhibitors reduce smooth muscle reactivity through an effect on calcium entry. ${ }^{13}$ Lack of oxygen diverts endogenous arachidonic acid from the cyclo-oxygenase to the lipoxygenase pathway and the metabolites that are formed accelerate the entry of calcium. 14-15 The excessive increase of cytoplasmic calcium leads to tissue hypoxia, loss of cellular function, and eventually structural damage. ${ }^{16}$ Raj and Chen showed that alveolar hypoxia leads to pulmonary arterial and venous constriction in isolated lamb lungs perfused with blood, ${ }^{17}$ and that leukotrienes mediate arterial and venous constriction with thromboxane $A_{2}$ being necessary for venous constriction. ${ }^{18}$ They concluded that the interaction between 5lipoxygenase and cyclo-oxygenase products of arachidonic acid results in the characteristic pulmonary hypoxic vasoconstrictor response.

Phospholipase $A_{2}$ in the vessel and platelet walls releases arachidonic acid, and thereby prostaglandins and thromboxanes, when activated. Prostacyclin $\left(\mathbf{P G I}_{2}\right)$ and prostaglandins $D_{2}$ and $E_{1}$ prevent platelet aggregation, whereas thromboxane $A_{2}$ (which is mainly released by platelets) promotes platelet aggregation. It is possible that a vasoactive, platelet aggregating substance such as thromboxane, released as a result of hypoxia or vascular endothelial injury, might in turn mediate both the platelet aggregation and the pulmonary hypertension. ${ }^{19}$ An association between persistent pulmonary hypertension of the newborn, thrombocytopenia, and platelet trapping with pulmonary microthrombi has been reported. ${ }^{3}$ Thromboxane seems to be crucial in mediating septic pulmonary hypertension, but not hypoxic pulmonary hypertension, which implies that different types of pulmonary hypertension may be mediated by different biochemical agents. ${ }^{20}$ Prostaglandin $\mathrm{E}_{1},{ }^{12} \mathrm{PGI}_{2}$, ${ }^{21}$ and prostaglandin $\mathrm{D}_{2}{ }^{22}$ have been used to try and reduce pulmonary hypertension, but with inconsistent results and many complications.

VASCONSTRICTIVE EFFECT OF CALCIUM

Contraction of the smooth muscle cells in the walls of blood vessels and the consequent reduction of tissue perfusion is initiated when the cytoplasmic free calcium concentration rises above $0.1 \mathrm{mmol} / \mathrm{l}^{16}{ }^{23}$ This increase could be the result of mobilisation of calcium from intracellular calcium pools or to increased permeability of the cell membrane to extracellular calcium because of the increase in endogenous vasoconstrictors, together with hypoxia or ischaemia. ${ }^{16} 23-24$

\section{CALCIUM CHANNEL BLOCKERS}

Pulmonary vasoconstriction is dependent on the availability of calcium to the affected cells, ${ }^{25}$ and so calcium channel blockers have been given in an attempt to induce pulmonary vasodilation. These agents can influence cardiovascular haemodynamics by a complex interplay of systemic arterial vasodilation, a negative inotropic effect, and reflex phenomena.

Calcium antagonists inhibit the activation of platelets by arachidonic acid, ${ }^{26}$ block the synthesis of thromboxane by platelets, ${ }^{27}$ and block thromboxane induced cerebral arterial constriction. ${ }^{28}$ Blockade of prostaglandin and thromboxane synthesis by indomethacin prevents pulmonary hypertension being caused by infection. ${ }^{29}$ Reeves et al showed that the calcium antagonists hydralazine and diazoxide had roughly equal effects in reducing acute pulmonary hypertension, but captopril had little effect. ${ }^{30}$ Verapamil and nifedipine both seem to reduce the pulmonary and systemic vascular pressures, but do not change the right to left shunt ratio in animals. ${ }^{31-32}$ In patients with primary pulmonary hypertension nifedipine decreased pulmonary and systemic vascular resistance, increased cardiac output, and improved the oxygenation of the blood but the ventilation:perfusion ratio deteriorated because there was an increased perfusion of units with low ventilation: perfusion ratios. ${ }^{32}$ Nitroprusside has been used with variable results and an overall $47 \%$ survival rate. ${ }^{33}$ Isoproterenol and noradrenaline, ${ }^{34}$ phenoxybenzamine, and chlorpromazine $^{35}$ have also been used as vasodilators in pulmonary hypertension with varying success. Tolazoline is the most widely used vasodilator, which has complex pharmacological effects including $\alpha$-adrenergic antagonism and agonism, cholinergic antagonism and agonism, and histaminergic agonism. ${ }^{36}$ Response to tolazoline is variable and predictors of success are unclear. About $70 \%$ of infants with persistent pulmonary hypertension of the newborn treated with tolazoline had a wide range of complications; only $59 \%$ of the infants improved and $54 \%$ survived. $^{36}$

Magnesium in pulmonary hypertension

Magnesium is an essential activator of about 300 
enzymes and is a necessary cofactor for ATPase. Thus magnesium is a vital cofactor in the maintenance of several energy demanding processes at the cellular level such as oxidative phosphorylation, neuromuscular excitability, and muscle contraction.

Lipman et al have shown that a continuous intravenous infusion of magnesium sulphate can control sympathetic crises and suppress the release of catecholamines. ${ }^{37}$ Magnesium sulphate also activates adenyl cyclase, which plays a part in the synthesis of cyclic AMP. ${ }^{38}$ increases in the amounts of cyclic AMP in smooth muscle promote relaxation by inhibiting the activity of myosin light chain kinase caused by accumulation of calcium by the sarcoplasmic reticulum, and resulting in a fall in intracellular free calcium to concentrations at which the myosin light chain kinase is not active. ${ }^{39}$ The effect of magnesium on cyclic AMP is of particular interest because there are data that suggest that increased cyclic AMP concentrations promote vasodilation. ${ }^{40}$ Magnesium sulphate causes peripheral arteries to dilate by various mechanisms. An indirect curare like action retards the release of acetylcholine and interferes with transmission at the neuromuscular junction and sympathetic ganglia. A direct action of the cation reduces the responsiveness of smooth muscle to sympathomimetic amines as well as to nonsympathomimetic vasopressors. ${ }^{3741-42}$ After an episode of ischaemic anoxia, concentrations of arachidonic acid rise rapidly in anoxic neurons. ${ }^{43}$ The influx of calcium ions to anoxic arterioles results in vascular spasm. ${ }^{44}$ In animal studies, magnesium antagonises calcium ion entry thereby promoting vasodilatation and alleviating the effect of severe hypoxia on the brain, liver, and kidneys. ${ }^{45-48}$

Thrombosis and consumption of platelets occur in small blood vessels in pulmonary hypertension. ${ }^{3} 19$ Magnesium has an antithrombotic effect which-at least theoretically - has a role in the treatment of pulmonary hypertension. ${ }^{49}$

In patients with severe hypertension of pregnancy, Cotton et al found that both systemic vascular resistance and pulmonary vascular resistance fell after magnesium sulphate was given, and by 30 minutes had returned to baseline values. ${ }^{50}$ McMurtry et al showed in isolated rat lungs that calcium antagonists inhibited hypoxic pulmonary vasoconstriction and that the hypoxic mechanism was critically dependent on the transmembrane influx of extracellular calcium. ${ }^{51}$ Similarly, inhibiting hypoxic vasoconstriction in dogs by increased plasma concentrations of magnesium chloride $^{52}$ was possibly related to calcium antagonism by magnesium. ${ }^{46-47}$ Cropp showed in dogs that there was a pronounced rise in pulmonary vascular resistance during hypoxia with normal concentrations of magnesium in the blood. As the magnesium concentrations were increased, the rise in pulmonary vascular resistance during hypoxia decreased. Hypoxic pulmonary vasoconstriction usually did not occur if magnesium rose above $5 \mathrm{mmol} / \mathrm{l}$. Magnesium concentrations of less than $6.5 \mathrm{mmol} / \mathrm{l}$ did not cause hypotension or hypoventilation. He concluded that a controlled increase in the blood magnesium concentration to 5-6 mmol/l will block hypoxic pulmonary vasoconstriction without causing deleterious changes in haemodynamics or pulmonary ventilation. Attempts to use magnesium to decrease the pulmonary hypertension that was induced by hypoxia were not investigated in these studies. ${ }^{52}$
Paidas et al showed that continuous infusion of ATP and magnesium chloride produced a significant decrease in mean pulmonary artery pressure after induced hypoxia with little or no systemic side effects. They also reported that magnesium chloride had no effect when infused alone. ${ }^{53}$ The doses of magnesium chloride given were small and the concentrations in serum were not measured. It is well known that a slight or moderate rise in blood magnesium does not affect the circulation. This study did, however, show the effect that magnesium preparations had in reducing pulmonary arterial pressure and resistance, and their likely useful therapeutic effect in pulmonary hypertension syndromes, but it failed to show the effect of magnesium alone because of the study design. Oral treatment with magnesium aspartate hydrochloride has been shown by Mathew et al to attenuate monocrotaline induced pulmonary hypertension, right ventricular hypertrophy, and pathological changes in the pulmonary vasculature in Wistar and Spraque-Dawley rats. ${ }^{54} \mathrm{Abu}-O$ sba $e t$ al showed in a placebo controlled study of anaesthetised and ventilated sheep that during induced hypoxia (by breathing 10\% oxygen) a sharp increase in the mean (SD) pulmonary artery pressure occurred from $16(2 \cdot 8)$ to $26(5 \cdot 3) \mathrm{mm} \mathrm{Hg}{ }^{55}$ During hypoxia there was no change in pulmonary arterial pressure $(27(5 \cdot 7) \mathrm{mm} \mathrm{Hg})$ after a placebo had been given. In contrast there was a sharp decrease after magnesium sulphate infusion (dose $200 \mathrm{mg} / \mathrm{kg}$, serum concentration $2.88 \mathrm{mmol} / \mathrm{l}$ ) in the right atrium; mean pulmonary arterial pressure was $25(5 \cdot 7)$ and $17(5 \cdot 6) \mathrm{mm} \mathrm{Hg}$ before and after treatment, respectively, $\mathrm{p}<0.001$. There was no change in the cardiac output and a transient decrease in the heart rate.

In severely sick infants born at full term with persistent pulmonary hypertension of the newborn and who did not respond to conventional treatment for 46-72 hours, magnesium sulphate was used as a vasodilator, a muscle relaxant, and a sedative (YK Abu-Osba $e t$ al, abstract presented at Paediatric Research Society Meeting, Leeds, March 1989). ${ }^{56}$ No other drugs were given or changes in the respirator settings or fractional inspiratory oxygen $\left(\mathrm{F}_{\mathrm{I}} \mathrm{O}_{2}\right)$ were made after the magnesium sulphate had been given unless oxygen tension rose; $\mathrm{F}_{\mathrm{I}} \mathrm{O}_{2}$ and respirator settings were then reduced. Four infants had $\mathrm{A}-\mathrm{aDO}_{2}$ gradients of over 84.5 , and one had an $\mathrm{A}-\mathrm{aDO}_{2}$ of $81.9 \mathrm{kPa}$, with predicted mortalities of $100 \%$ and $94 \%$, respectively. After treatment with magnesium sulphate, mean (SD) oxygen tensions and haemoglobin oxygen saturation increased significantly within six hours from $4.3(1.9)$ to $11.8(7.6) \mathrm{kPa}$, $\mathrm{p}<0.04$, and 58 (30) to 95 (5)\%, respectively $(p<0.03)$. One infant died with a persistent $\mathrm{A}-\mathrm{aDO}_{2}$ of over $84.5 \mathrm{kPa}$. None had intraventricular haemorrhage, bronchopulmonary dysplasia, or bradycardia requiring intervention.

These studies show that magnesium is beneficial in reducing hypoxia induced pulmonary hypertension in both animals and in full term infants with persistent pulmonary hypertension of the newborn. Its efficacy in preterm infants and for other non-hypoxic causes of pulmonary hypertension should be investigated. Some reports have described a beneficial vasodilating effect together with reduction of complications after ischaemic hypoxia in the central nervous system, heart, kidneys, and liver. ${ }^{45}$ 46-48 These conditions frequently coexist with pulmonary hypertension and severe hypoxaemia in neonates. Though a controlled multi- 
centre large study is required before recommending magnesium as a first line of treatment, these studies suggest its possible benefits in persistent pulmonary hypertension of the newborn when conventional treatment has failed, is contraindicated, or is unavailable. Close monitoring of blood pressure, kidney function, glucose calcium concentrations should be undertaken. Long term follow up is needed.

I thank Professor RDG Milner for helpful discussion and criticism.

1 Haworth SG, Reid L. Persistent fetal circulation: newly recognized structural features. F Pediatr 1976;88:614-20.

2 Rudolph AM. Fetal and neonatal pulmonary circulation. Annu Rev Physiol 1979;41:383-95.

3 Levin D, Weinberg A, Perkin R. Pulmonary microthrombi syndrome in newborn infants with unresponsive persisten
pulmonary hypertension. $\mathcal{F}$ Pediatr 1983;102:299-303.

4 Fox WW, Duara S. Persistent pulmonary hypertension of the neonate: diagnosis and clinical management. $\mathcal{f}$ Pediatr 1983;103:505-8.

5 Krummel TM, Greenfield LJ, Kirkpatrick BV, et al. Alveolar-arterial oxygen gradients versus the neonatal pul Alveolar-arterial oxygen gradients versus the neonatal pul-
monary insufficiency index for prediction of mortality in monary insufficiency index for prediction of mortality

6 Davis JM, Spitzer AR, Cox C, Fox WW. Predicting survival in infants with persistent pulmonary hypertension of the newborn. Pediatr Pulmonol 1988;5:6-9.

7 Anonymous. Persistent fetal circulation and extracorporeal membrane oxygenation [Editorial]. Lancet 1988;ii:1289-91.

8 Wegman ME. Annual summary of vital statistics-1981. Pediatrics 1982;70:835-43.

9 Sell EJ, Gaines JA, Guckman C, et al. Persistent fetal circula tion. Neurodevelopmental outcome. Am $\mathrm{f}$ Dis Child 1985;139:25-8.

10 Bartlett RH, Roloff DW, Cornell RG, et al. Extracorporeal circulation in neonatal respiratory failure: a prospective randomized study. Pediatrics 1985;76:479-87.

11 Wung JT, James LS, Kilchevsky E, et al. Management of infants with severe respiratory failure and persistence of the fetal circulation, without hyperventilation. Pediatrics 1985;76:488-94.

12 Philips III JB. Prostaglandin and related compounds in the perinatal pulmonary circulation. Pediatric Pharmacology $1983 ; 4: 129-42$.

13 Higgs GA, Mugridge KG, Moncada S. Arachidonic acid metabolism and calcium flux. In: Godfraind T, Vanhoutte PM, Stefano G, Paoletti R, eds. Calcium entry blockers and tissue protection. New York: Raven Press, 1985:51-8.

14 Rimele TJ, Vanhoutte PM. Effects of inhibitors of arachidonic acid metabolism and calcium entery on responses to acetylcholine, potassium and norepinephrine in the isolated canine saphenous vein. $\mathcal{f}$ Pharmacol Exp Ther
1983;225:720-8.

15 Van Nueten JM, Vanhoutte PM. Effect of the $\mathrm{Ca}^{++}$antagonist lidoflazine on normotoxic and anoxic contractions of canine coronary arterial smooth muscle. Eur 7 Pharmacol 1980;64:173-6.

16 Van Nueten JM. Calcium entry blockers and vascular smooth muscle reactivity. In: Godfraind T, Vanhoutte PM, Stefano G, Paoletti R, eds. Calcium entry blockers and tissue protection. New York: Raven Press, 1985:69-79.

17 Raj JU, Chen P. Micropuncture measurement of microvascular pressures in isolated lamb lungs during hypoxia. Circ 1986;59:398-404.

18 Raj JU, Chen P. Role of eicosanoids in hypoxic vasoconstric tion in isolated lamb lungs. Am 7 Physiol 1987;253:H626-

19 Morrow W, Haas J, Benjamin D. Nonbacterial endocardial thrombosis in neonates: relationship to persistent fetal circulation. F Pediatr 1982;100:117-22.

20 Hammerman C, Komar K, Abu-Khudair H. Hypoxic vs septic pulmonary hypertension. Am $\mathcal{F}$ Dis Child 1988;142:319 25.

21 Kaapa P, Koivisto M. Ylikorkala O, Kouvalainen K. Prostacyclin in the treatment of neonatal pulmonary hypertension. $\mathcal{F}$ Pediatr 1985;107:951-3.

22 Phillips III JB, Lyrene RK, McDevitt M, et al. Prostaglandin D2 inhibits hypoxic pulmonary vasoconstriction in neonatal lambs. F Appl Physiol 1983;54:1585-9.

23 Bolton TB. Mechanisms of action of transmitters and other substances on smooth-muscle: review. Physiol Rev 1979;59:606-718.

24 Karaki H, Kubota H, Urakawa N. Mobilization of stored calcium for phasic contraction induced by norepinephrine in rabbit aorta. Eur $\mathcal{f}$ Pharmacol 1979;56:237-45.

25 Bohr DF. The pulmonary hypoxic response. Chest 1977;71(suppl):244-6.
26 Johnson $\mathbf{H}$. Effects of nifedipine on platelet function in vitro and in vivo. Thromb Res 1981;21:523.

27 Addonizo VP, Fischer CA, Ecmunds LH. Effects of verapamil and nifedipine on platelet activation. Clin Res 1980;28:607A

28 Towart R, Perzborn E. Nimodipine inhibits carbocyclic thromboxane-induced contractions of cerebral arteries. Eur 7 Pharmacol 198 $369: 213-5$.

29 Rojas J, Green RS, Hellerqvist CG, et al. Studies on group Bhemolytic streptococcus. II. Effects of pulmonary hemodynamics and vascular permeability on unanesthetized sheep. Pediatr Res 1981;15:899-904.

30 Reeves JT, Groves BM, Turkevich D. The case for treatment of selected patients with primary pulmonary hypertension. Am Rev Respir Dis 1986:134:342-6.

31 Dickstein PJ, Trindad O, Goldberg RN, Bancalar E. The effect of calcium antagonists on hypoxic pulmonary hypertension in the piglet. Pediatr Res 1984;18:1262-5.

32 Melot C, Naeije R, Mols P, et al. Effects of nifedipine on ventilation/perfusion matching in primary pulmonary hypertension. Chest 1983;83:203-7.

33 Benitz WE, Malachowski N, Cohen RS, et al. Use of sodium nitro-prusside in neonates: efficacy and saftey. $\mathcal{F}$ Pediat 1985;106:102-10.

34 Ducas J, Duval D, Dasilva H, Boiteau P, Prewitt RM. Treatment of canine pulmonary hypertension: effects of norepinephrine and isoproterenol on pulmonary vascular pressure-flow characteristics. Circulation 1987;75:235-42.

35 Larsson LE, Ekstrom-Jodal B, Hjalmarson O. Effect of chlorpromazine in severe hypoxia in newborn infants. Acta Paediatr Scand 1982;71:339-402.

36 Roberts RJ. Cardiovascular drugs. Drug therapy in infants, pharmacologic principles and clinical experience. Philadelphia: WB Saunders, 1984:192.

37 Lipman J, James MF, Erskine J, Plit ML, Eidelman J, Esser JD. Autonomic dysfuction in severe tetanus: magnesium sulfate as an adjunct to deep sedation. Crit Care Med

38 Altura BM, Altura BT. Magnesium ions and contraction of vascular smooth muscles: relationships to some vascular diseases. Federation Proceedings 1981;40:2672-9.

39 Huszar G, Roberts JM. Biochemistry and pharmacology of the myometrim and labor: regulation at the cellular and molecular levels. Am 7 Obstet Gynecol 1982;142:225-37.

40 Kramer GL, Hardman JG. Cyclic nucleotides and blood vessel contraction. In: Bohr DF, Somlyo AP, Sparks HV Jr, eds. Handbook of physiology. Vascular smooth muscle. Vol 2. Baltimore: Williams and Wilkins, 1980:179-99.

41 Levowitz BS, Goldson H, Rashkin A, et al. Magnesium ion blockade of regional vasoconstriction. Ann Surg 1970;172:33-40.

42 Froh.lich ED, Scott JB, Huddy FJ. Effect of cations on resistance and responsiveness of renal and forelimb vascular beds. Am F Physiol 1962;203:583-7.

43 Aveldano MI, Bazan NG. Rapid production of diacylglycerols enriched in arachidonate and stearate during early brain ischemia. F Neurochem 1975;25:919-20.

44 Van Neuten JM, Vanhoutte PM. Improvement of tissue perfusion with inhibitors of calcium ion influx. Biochem Pharmacol 1980;29:479-81.

45 Altura BT, Altura BM. Interactions of $\mathrm{Mg}$ and $\mathrm{K}$ on cerebral vessels-aspects in view of stroke. Review of present status and new findings. Magnesium 1984;3:195-211.

46 Turplapaty PD, Altura BM. Extracellular magnesium ion control calcium exchange and content of vascular smooth muscle. Eur f Pharmacol 1978;52:421-3.

47 White BC, Winegar CD, Wilson RF, Krause GS. Calcium blockers in cerebral resuscitation. $\mathcal{f}$ Trauma 1983;23:78894.

48 Clemens JG, McDonaggh PF, Chaudry IH, et al. Hepatic microcirculatory failure following ischemia and reperfusion: improvement with ATP-MgCl2 treatment. $\mathrm{Am} \mathcal{f}$ Physiol 1985;248:H804-11.

49 Anstall HB. The effect of magnesium on blood coagulation in human subjects. Lancet 1959;i:814-5.

50 Cotton DB, Gonik B, Dorman KF. Cardiovascular alterations in severe pregnancy-induced hypertension: acute effects of intravenous magnesium sulfate. $A m \mathcal{y}$ Obstet Gymecol 1984;148:162-5.

51 McMurtry IF, Davidson AB, Reeves JT, Grover RF. Inhibition of hypoxic pulmonary vasconstriction by calcium antagonists in isolated rat lungs. Circ Res 1976;38:99-104.

52 Cropp GJA. Reduction of hypoxic pulmonary vasoconstriction by magnesium chloride. 7 Appl Physiol 1968;24:755

53 Paidas CN, Dudgeon DL, Haller JA Jr, Clemens MG. Ade nosine triphosphate: a potential therapy for hypoxic pulmonary hypertension. $\mathcal{f}$ Pediatr Surg 1988;23:1154-60.

54 Mathew R, Altura BT, Altura BM. Strain differences in pulmonary hypertensive response to monocrotaline alkaloid and the beneficial effect of oral magnesium treatment. Magnesium 1989;8:110-6.

55 Abu-Osba YK, Rhydderch D, Balasundaram S, et al. Reduction of hypoxia-induced pulmonary hypertension (HIPH) by $\mathrm{MgSO}_{4}$ in sheep. Pediatr Res 1990;27:351A.

56 Abu-Osba YK, Manasara K, Galal O, Rejial A. Treatment of pulmonary hypertension of newborn (PPHN) with magnesium. Pediatr Res 1990;27:294A. 